\title{
Red Tacton Technology
}

\author{
K. Subbulakshmi, S. Ramya, M. Jasmine
}

\begin{abstract}
All user friendly services need technologies that allow communication among people and object in a more closer proximity. This is possible through a distinct wireless technology called as - RED TACTON TECHNOLOGY. It is a human area networking technology, which was initially developed by Robbin Gaur Jind. This paper explains in detail about the working of technology and why it must be chosen over other technologies. We all know that wireless technologies like Bluetooth and infrared are over-rated now-a-days. Now researchers are trying to advance a new path for transmission of signals called Human Area Networking. This networking uses our body as a transmission medium to transfer data. It uses the electric field generated on the surface of the body. It detects the user's physical movements and performs tasks according to the instruction given. When the transceiver comes in contact with the human body a transmission path is formed. Red Tacton works through shoes and clothing as well. Communication through body surfaces such as the hands,torso,feet,face,legs can be made possible using this technology. The human body itself acts as a transmission medium supporting half duplex communication at

10Mbps. Sensor equipped with an electro optic crystal and laser light is the major component of transceiver. Even communication plays an important role in the field of networking which has resulted into creation of many tools such as card readers in ATM pin . but the existing methods are not secure enough so if this technology is implemented in a right way then this can make all the control systems more secure and user friendly where human body acts as the only medium for transmission of data.
\end{abstract}

Keywords -RedTacton,Networking Technology, Transmission, Electroopticcrystal,Transceiver

\section{INTRODUCTION}

Communication in today's world has become easier. People can convey and receive information from around the globe within seconds with the help of cellphone. Internet allows users to gather or download huge amount of data from even remote areas. All these technologies have made human communication and interaction more ambient. Wearable computers too are hectic and can get entangled. Wireless communications have started too overshadow the existence of such computers and otherwired devices suchas PDAs. Wireless communications overa small range suchas Bluetooth(IEEE 802.11b)facesome problems in out comesas the signals can be intercepted in a crowded locality [1-5].

Revised Manuscript Received on July 22, 2019.

K.Subbulakshmi Department of Electronics and Communication Engineering, Bharath Institute of Higher Education and Research, Chennai, India

S. Ramya, Department of Electronics and Communication Engineering, Bharath Institute of Higher Education and Research, Chennai, India

M. Jasmine, Department of Electronics and Communication Engineering, Bharath Institute of Higher Education and Research, Chennai, India
In additiontothis,thepresent modeofcommunicationfaces severechallengefromupcoming modeofcommunication whichisnothingbutus,the humanbeings.all the existing technologies are suffering from signal interception which plays a major problem in networking . with communication security playinga major role authentication and authorization is required.In order to support this requirement many tools have been created such as card readers in ATM,pin codes .but there was drawback that these tools were not fraud proof, we moved to biometric type of systems where the fingerprints and retina scans of the user helps him in accessing control . so we have seen that there are many methods followed all over the world. This paper is organized as follows : Section I describes about Red Tacton, Section II discusses about red tacton.Section III explains the working principle .Section IV discusses about features of red tacton. Section V discusses about the application in several aspects.In section VI comparison is done . In section VII future scope is discussed .section VIII gives the conclusion for this technology [6-8].

\section{REDTACTON}

The NTT labs in Japan are working on this challenging method known as the REDTACTON TECHNOLOGY. RedTacton represents action triggered by touching in this technology the human body serves as the medium for communication. This would be an advantageous wayofimplementing humanareanetworkasitcouldsortout allproblemssuchasreductioninthroughput, security problems,highnetwork setupcostsandseveralotherissues. Humanbodygenerates asmallelectricfieldwhichactsasthe transmittingmediumfordata.Inthis,smallchipscontaininga transmitterandreceiverto sendandreceivedataareembedded inourbody. Theinstantourbody partcomes incontactwith theRedTactontransceiver,itformsatransmission path.The terminalsareeitherembedded inthedevicesorarecarriedby theuseritself.In fig .(a) shows the schematic of the Red Tactontechnology Communicationcan bethrough any partofthebody such ashands, legsorarms orany partofthe body.Thistechnologyhastwolimitationswhichare1.range ofoperation throughthebodywaslimitedtofewtenof centimeters 2.highest communication range was only $40 \mathrm{Kbits} / \mathrm{seconds}$. Thesewerebecauseoftheuseofelectricals ensors.Electricalsensorconsistsoftwolines-1 signalline and1groundline [9-11]. 


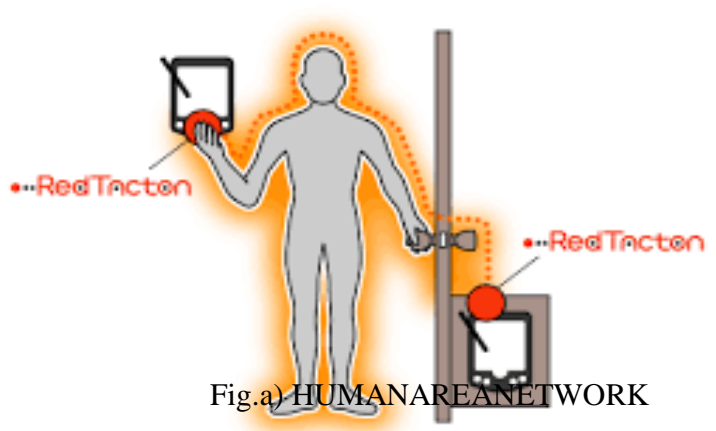

III. WORKING PRINCIPLE

Fig(b)explains the working principle of Red Tacton Technology.

The data sense circuit and transmitter circuit receive signals from the interface. The transmitter will now induce small electric field on human body surface. Thedata sensecircuit detects the signal and in the presence of the data, it sends control signals to the transmitter. The transmitter circuit gets activated by this signal. The electricfield on the surface of the body is varied by the transmitter circuit, which is identified by the electro-optic sensor. Atransistororthe photonic electric field sensor will be setup as the sensor for the electric field on the receiver part. This sensor detects the electric field and signal will be processed in receiver as well. This processed signal is the data to be downloaded. The signals,as the digital signals, depend on the variations in the induced electric field. As the electric field nducedisvery mild, high sensitivity sensing technologies are used in the receiverpart.Apartfrom theelectricfieldinduced,therewill beothersmallorunstable electricfields onthesurfaceofthe body.Thesewillbenaturalandwillbeautomaticallysent backtoearth [12-15].

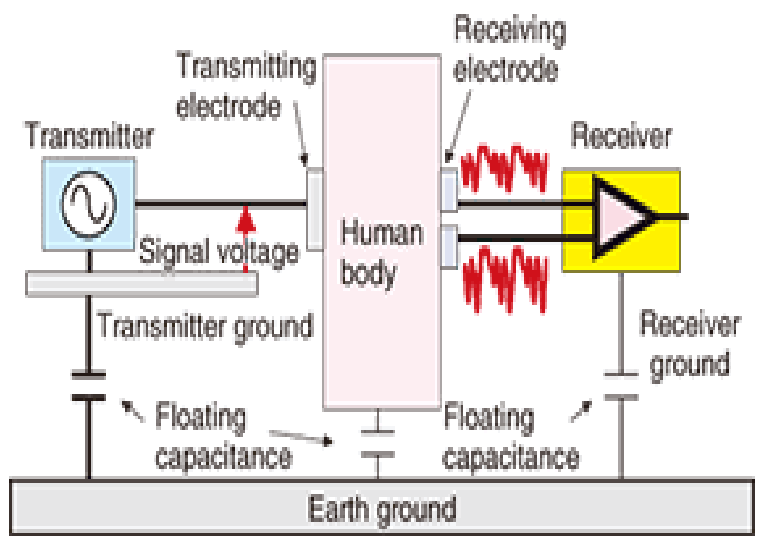

Fig.(b)RED TACTON TRANSCEIVERBLOCK DIAGRAM

\section{FEATURES OFREDTACTON}

\section{A. Touch Feature}

In this, communication isdonewithasimpletouch. Physical movements such as walking, gripping, touching are all used as triggers for various processes of the equipment. These process include START and STOP of the equipment, data retrieval, locking and unlocking data.

\section{B. Broadband Feature}

Theidealspeedusingthismethodis10Mbps for broad band communication, which is constant forfull- duplex communication. The speed of communication will notbeaffectedeven incaseofmultiple communications since thetransmission of signal takes place through humanbody.

\section{Anymedium}

Besides human body, there are several other conductors which can be used for communication.

Fig.(c) explains the features of red tacton technology in a diagrammatic form .

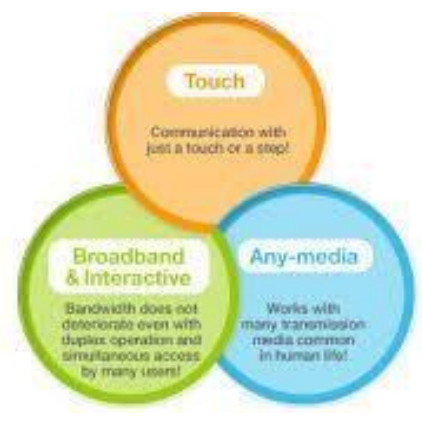

\section{APPLICATIONS}

\section{A. An alarm sound to avoid accidental medicine intake}

A red tacton transceiver is placed in the medicine bottle which transits the information about the medicine. When the user picks the wrong medicine,an alarm is triggered. The alarm buzzes only when the user comes in actual contact with the medicine bottle.

\section{B. Touch advertising and information reception}

The attribute of the consumer is displayed automatically when they touch or stand in front of the advertising panel they are interested in.

Fig(d) explains the various applications of red tacton technology.

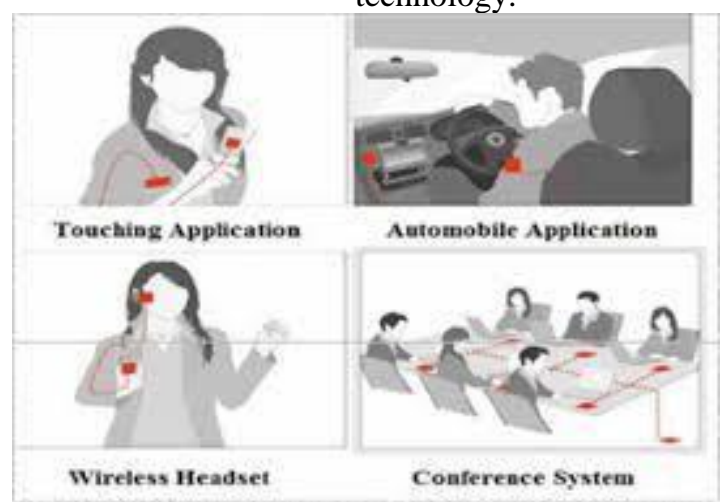

Fig.(d)APPLICATIONS

\section{Payments made easy}

Our phone numbers are storedinvariousshopsandbilling startsautomaticallywhenour transmittercomesin contact with their receiver. 


\section{Advanced car features}

Theseatposition andsteeringwheelheightareadjusted automaticallyaccordingdriver'sdesirejustbysittinginthe car[5].Thedriver'shomeisalsosetasdestination inthecar navigationsystem.Driver'sfavoritesongisalsoplayedas soonasheentersthecar.

\section{E. Conference system}

Byembeddingan electricallyconductivesheetonthetablethe networkconnection inourlaptopisinitiatedassoonasthe laptopisplaced onthetable.Changeinsheetpatterns enables to segmentthetableintosubnets

\section{F. Security application}

WhentheusercarriesaRedTactonsupporting deviceinhis pocketandtouchesthedoorknob, hisidentity isverifiedand the door is unlocked .It can be made more secured by includingpersonalverification toolssuchasfingerprints or otherbiometricsinmobileterminal.

\section{G. Military applications}

One red tacton transceiver can be placed in the un which is programmed to the other transceiver that is with the soldier. In this way only that particular soldier can fire the weapon. This reduces the misuse of stolen weapons and decrases the black marketing of weapons [16-18].

\section{COMPARISON WITH OTHER NETWORKS}

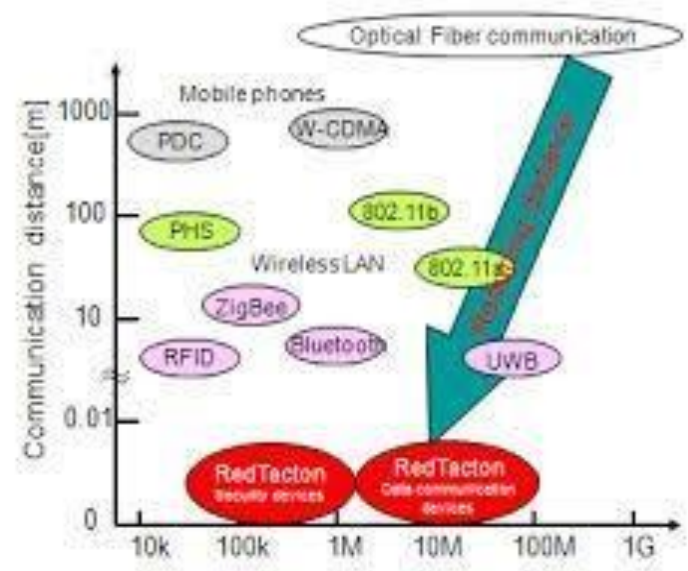

Fig.(e)COMPARISON GRAPH

In Fig.(e) the comparison of this technology is done with other existing technologies. When compared withwiredtransmission RedTactonrequires higherrateofphysicalconnection fordatatransmissionwhen moreusertrytoretrievedatafrom thesinglesourcethe physicalconnections becomedifficultbutitwouldnotaffect the securityofthedata.

Hence we infer that Red Tacton technology lies in between wireless andwiredcommunication. Itprovidesmaximum security anddataHenceweinferthatRedTactontechnology liesinbetweenwirelessandwiredcommunication.Itprovides maximum securityand data transfer without the use of physicalconnections thesecurity ishighasthedatais transferred onlybetween twocontactpoints. Transferwithout theuseofphysicalconnectionsthesecurity ishighasthedata istransferredonlybetweentwocontactpoints.Fig(e)gives thecomparison ofredtactontechnology withotherwireless technologies.

\section{ADVANTAGES}

1.Data transfer is faster and easier through this technology

2.Datalossduringtransferisless

3.Useofminimum amountofpower(ofsomemillivolt range)

4.Securityismore

5.Lesscharging

6.Itdoesnotrequiretheelectrode tobeindirectcontact withtheskin

7.Thetransceiversareprogrammable andwecandecide what tosharewithwhom andwhat devices you communicatewith. 8.Noproblemofhackers.itisveryhardtopickupstray electronicsignalsradiatingfromthebody.

\section{DISADVANTAGES}

1. It will be comparatively expensive

2. Continuous use of this technology may cause harmto the bodyasituseselectricfieldsonthesurfaceofthe body $[19,20]$.

\section{FUTURE DEVELOPMENTS}

WhenausercarryingaRedTactondeviceoranyspecialcard walksthroughrailwayverification gate,thedatawill pass throughtheusersclothingorshoeswhichcanunlockthegate

.it hasmanyother futureapplicationsuchas personalized cabinets which opens for authorized person,choosing our favourite channels by television remote controls, unlocking car doors with our personalized keys which does not aloow access to outsiders. It ensuresthatonly the driverscanopentheircarsbytouchingthedoorsthekeys areintheirpockets .Ithasotherbenefits likesharingfilesor imagesamongagroupofpeoplewithoutanydelay .whenit comestosecuringpersonalinformationssuchasbankdetails, importantpasswords RedTactonplaysavitalroleby providingonetooneservice.inthistechnology datacanbe transferredatspeedof10mbps.Inthiswaywireless data transmission and communication in future is taken to differentheightsbyprovidingmore securityand abundant features.

\section{CONCLUSION}

Red Tacton technology is an advanced method in human area networking. It uses human body as the transmission path based on the electric field sensor which uses a laser light and electro optic crystal. While the present objective of this technology is to introduce a network supporting two way Intra-body communication between any two points on the body atarateof $10 \mathrm{mbps}$, the longer term plans include to enhance the portability by bringing down the size and also by decreasing the power consumption. 


\section{REFERENCES}

[1] Kongkham, D. \& Sundararajan, M. 2019, "Distributed wideband sensing method for faded dynamic spectrum access", International Journal of Innovative Technology and Exploring Engineering, vol. 8, no. 10 , pp. 4309-4312.

[2] Balaji, S., John Paul Praveen, A. \& Mohanraj, R. 2019, "Recognizable proof and analysis of palm print in biometric authentication system using bayes techniques", International Journal of Innovative Technology and Exploring Engineering, vol. 8, no. 9 Special Issue 3, pp. 1126-1129.

[3] Kavitha, G., Priya, N., Velvizhi, R. \& Allin Geo, A.V. 2019, "Parallel computation in correspondence and signal processing", International Journal of Innovative Technology and Exploring Engineering, vol. 8, no. 9 Special Issue 3, pp. 1136-1139.

[4] Hema, R., Sundararajan, M. \& Balaji, S. 2019, "Smartphone control robot with automatic firing gun", International Journal of Innovative Technology and Exploring Engineering, vol. 8, no. 9 Special Issue 3, pp. 625-627.

[5] Kaliyamurthie, K.P., Sundar Raj, B., Velvizhi, R. \& Shanmugapriya, K. 2019, "Dual band paper substrate CPW antenna for wireless applications", International Journal of Innovative Technology and Exploring Engineering, vol. 8, no. 9 Special Issue 3, pp. 605-608.

[6] Geo, A.V.A., Arunachalam, A.R., Michael, G. \& Elankavi, R. 2019 "Evaluating architecture using compact modalities", International Journal of Innovative Technology and Exploring Engineering, vol. 8, no. 9 Special Issue 3, pp. 836-838.

[7] Theivasigamani, S., Jeyapriya, D. \& Anita Davamani, K. 2019, "Anamoly analyzing and exploring for wireless sensor networks", International Journal of Innovative Technology and Exploring Engineering, vol. 8, no. 9 Special Issue 3, pp. 1116-1118.

[8] Jeyapriya, D., Theivasigamani, S., Velvizhi, R. \& Nandhini, P. 2019, "Program detection in wireless feeler networks", International Journal of Innovative Technology and Exploring Engineering, vol. 8, no. 9 Special Issue 3, pp. 1194-1195.

[9] Gowri Sankaran, B., Karthik, B. \& Vijayaragavan, S.P. 2019, "Image compression utilizing wavelet transform", International Journal of Innovative Technology and Exploring Engineering, vol. 8, no. 10, pp. 4305-4308.

[10] Gowri Sankaran, B., Karthik, B. \& Vijayaragavan, S.P. 2019, "Weight ward change region plummeting change for square based image huffman coding", International Journal of Innovative Technology and Exploring Engineering, vol. 8, no. 10, pp. 4313-4316.

[11] Hema, R., Sundararajan, M. \& Balaji, S. 2019, "Smartphone control robot with automatic firing gun", International Journal of Innovative Technology and Exploring Engineering, vol. 8, no. 9 Special Issue 3, pp. 625-627.

[12] Rangaswamy, K. \& Rajabhushanam, C. 2019, "Congestion control in wireless network using TCP friendly rate control (TFRC)", International Journal of Recent Technology and Engineering, vol. 8, no. 2 Special issue 3, pp. 1598-1602.

[13] Tamil Selvan, S. \& Sundararajan, M. 2019, "Performance Parameters of 3 Value 8t Cntfet Based Sram Cell Design Using H-Spice", International Journal of Recent Technology and Engineering, vol. 8, no. 2 Special issue 5, pp. 22-27.

[14] Vinoth, V.V. \& Kanniga, E. 2019, "Steganographical techniques in hiding text images - system", International Journal of Recent Technology and Engineering, vol. 8, no. 2, pp. 6535-6537.

[15] Saravana, S., Balaji, S., Arulselvi, S. \& John Paul Praveen, A. 2019, "Reliable power quality monitoring and protection system", International Journal of Innovative Technology and Exploring Engineering, vol. 8, no. 9 Special Issue 3, pp. 644-645.

[16] Sundaramoorthy, A. \& John Wiselin, M.C. 2019, "Single patch antenna with multiple feed", International Journal of Innovative Technology and Exploring Engineering, vol. 8, no. 9, pp. 1743-1747.

[17] Velavan, R., Bharanidharan, S. \& Sheeba, B. 2019, "EMF pollution Causes, effects and protection", International Journal of Innovative Technology and Exploring Engineering, vol. 8, no. 9 Special Issue 3, pp. 1166-1168

[18] Veer, R.A., Arulselvi, S. \& Karthik, B. 2019, "Construction of ensemble square classification approaches in MIMO OFDM", International Journal of Engineering and Advanced Technology, vol. 8, no. 5 , pp. 2039-2041.

[19] Agitha, W. \& Kaliyamurthie, K.P. 2019, "Improved energy efficient in WBAN using MAC with cloud computing", International Journal of Innovative Technology and Exploring Engineering, vol. 8, no. 8, pp. 2405-2408.
[20] Kastro, G.G. \& Wiselin, M.C.J. 2019, "Design and analysis of stub loaded resonator", International Journal of Recent Technology and Engineering, vol. 8, no. 1 Special Issue4, pp. 272-283.

\section{AUTHORS PROFILE}

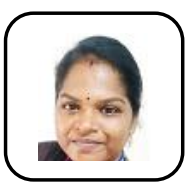

K.Subbulakshmi Assistant Professor, Department of Electronics and Communication Engineering, Bharath Institute of Higher Education and Research, Chennai, India

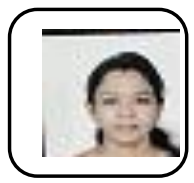

S. Ramya Assistant Professor, Department of Electronics and Communication Engineering, Bharath Institute of Higher Education and Research, Chennai, India

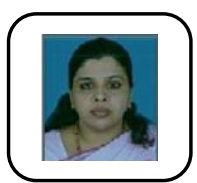

M. Jasmine Assistant Professor, Department of Electronics and Communication Engineering, Bharath Institute of Higher Education and Research, Chennai, India 